\title{
A Perspective on Strategic Enrichment for Brain Development: Is This the Key to Animal Happiness?
}

\author{
Dana L. M. Campbell* and Caroline Lee \\ Agriculture and Food, Commonwealth Scientific and Industrial Research Organisation (CSIRO), Armidale, NSW, Australia
}

Livestock animals are sentient beings with cognitive and emotional capacities and their brain development, similar to humans and other animal species, is affected by their surrounding environmental conditions. Current intensive production systems, through the restrictions of safely managing large numbers of animals, may not facilitate optimal neurological development which can contribute to negative affective states, abnormal behaviors, and reduce experiences of positive welfare states. Enrichment provision is likely necessary to enable animals to reach toward their neurological potential, optimizing their cognitive capacity and emotional intelligence, improving their ability to cope with stressors as well as experience positive affect. However, greater understanding

OPEN ACCESS

Edited by:

Jeremy N. Marchant,

Livestock Behavior Research Unit (USDA-ARS), United States

Reviewed by: Jen-Yun Chou, University of Pennsylvania, United States Jamie Ahloy-Dallaire, Laval University, Canada

*Correspondence:

Dana L. M. Campbell dana.campbell@csiro.au

Specialty section: This article was submitted to Animal Behavior and Welfare, a section of the journal

Frontiers in Veterinary Science

Received: 04 June 2021

Accepted: 25 August 2021

Published: 21 September 2021

Citation:

Campbell DLM and Lee C (2021) A Perspective on Strategic Enrichment for Brain Development: Is This the Key to Animal Happiness?

Front. Vet. Sci. 8:720422. doi: 10.3389/fvets.2021.720422 of the neurological impacts of specific types of enrichment strategies is needed to ensure enrichment programs are effectively improving the individual's welfare. Enrichment programs during animal development that target key neurological pathways that may be most utilized by the individual within specific types of housing or management situations is proposed to result in the greatest positive impacts on animal welfare. Research within livestock animals is needed in this regard to ensure future deployment of enrichment for livestock animals is widespread and effective in enhancing their neurological capacities.

Keywords: emotional intelligence, cognition, neuro, welfare, affective state, behavior, livestock

\section{INTRODUCTION}

Livestock animals are sentient beings (1) with proven cognitive capacity and thus cognitive needs. These animals are capable of learning, self-control, self-awareness, show cognitive biases and have complex social relationships (2-5). They are also capable of experiencing emotions or affective states such as fear, anxiety, pleasure and potentially depression (6-9). Commercial livestock farming typically raises animals in less complex environments, when compared with what wild counterparts would experience. This reflects the logistics and economics of large-scale animal production, as well as consideration of injury, health, and disease risks that may come with increased environmental complexity. Thus, the animals may be healthy, but may not "have what they want" (10). These more controlled and simpler conditions can often result in undesirable behavioral patterns. High frequencies of abnormal behaviors such as stereotypies (11) and injurious inter-individual interactions [e.g., tail biting in pigs: (12); feather pecking in laying hens: (13)] indicate the environmental conditions may be suboptimal, contributing to welfare and production impacts. With the realization that sentient animals may not be best suited to less complex environments, an animal welfare focus over recent decades has driven a trend toward improving animal housing conditions to increase environmental and social complexity 
for enrichment purposes. Environmental complexity can be provided in many different forms to be enriching [i.e., physical, sensory, social, occupational, nutritional; (14)]. For this increased complexity to be termed "environmental enrichment," the environmental modification must result in improved biological functioning of the captive animal (15). Enrichment when effective could include physical modifications to the environment through structural changes, cognitive challenges such as puzzles or learning tasks, social changes such as group vs. single housing, enhanced sensory stimulation such as music playback, or feeding variation that may stimulate foraging behavior. Commercially, some examples include the banning of conventional laying hen cages across several regions in favor of aviaries and furnished cages with valued resources such as perches and nest boxes (16); and the revision of farmed mink guidelines in Canada to include compulsory cage enrichment provision of manipulable objects (17).

While these increases in environmental complexity are a step in the right direction, they may not yet be enough to result in the desired animal welfare improvements in livestock species such as poultry, ruminants, pigs, and mustelids. In particular, while current enrichment interventions may help alleviate negative affective states by providing resources to meet an animal's behavioral needs, more may be required to encourage experience of positive affective states (8). Affective states are important in welfare assessment and have a direct relationship with affective neuroscience $(8,9)$. Thus, consideration of the neurological impacts of rearing (birth/hatching until maturity or slaughter age) and adult housing conditions (where animals may change housing environments once maturity is reached) must be made to ensure enrichment programs are achieving the desired positive impacts. Enrichment programs may need to be applied strategically to ensure an individual animal is best suited to the environmental conditions it will experience throughout its production life. This could include several different types of environments for animals that change housing across life stages (e.g., laying hens are reared in one facility and are moved to a different facility for the adult laying period). Enrichment is likely also critical for livestock in the prenatal period (i.e., pregnancy and incubation) and even prior [e.g., parent-stock impacts on subsequent chick development in laying hens: (18)] but the postnatal period will be the primary focus here. This perspective review explores the relationship between enrichment, developmental environments, neurological impacts, cognitive and emotional intelligence in livestock animals and the goal of positive welfare states drawing on evidence across humans and other animals where livestock research is limited.

\section{Defining Cognition and Emotion}

Cognition is the term used for the mental thought processes of acquiring knowledge about the environment through learning, perception, and judgment as well as the manipulation and retrieval of this knowledge. Social cognition is the processing of information related to other individuals. Cognitive capacity is thus the ability that an individual or species has to carry out these actions, allowing understanding of the surrounding world. Emotions are the feelings that are experienced relative to specific situations and experiences. Emotional intelligence (EI) as first proposed by Salovey and Mayer (19), is defined as "the ability to monitor one's own and others' feelings and emotions, to discriminate among them and to use this information to guide one's thinking and actions" (p. 189). Emotional intelligence has been further divided into "ability EI" which measures an individual's theoretical understanding of emotions, compared with "trait EI" which measures how an individual may typically respond to an emotional situation (20). Multiple measures have been developed for assessing EI in humans, although it is still challenging to objectively quantify a comparatively abstract type of intelligence (21). While self-report assessment tools are not possible in animal research, performance in emotionally relevant situations allows measurement of EI in livestock. The specific term of EI is not frequently used in the animal-based literature but studies do indicate the presence of EI when compared with the descriptions in the originally proposed EI framework (19). For example, conditioned place preference/avoidance tests suggest livestock animals are able to avoid/seek previous negative or positive emotional experiences (22-24) indicating self-regulation of emotional states. Pigs show evidence of emotional contagion where naïve animals will recognize and respond according to the positive or negative emotional state of conspecifics $(25,26)$. There is also some evidence of empathetic behaviors across other livestock animals although the research is limited (27). Furthermore, individual variation in animal adaptation to new environments, appropriate vs. inappropriate (extreme) fear reactions to external stimuli, and performance in tasks that elicit conflicts in the animal in their focus (e.g., attention bias testing, or learning a new maze task) are all potential indicators of degrees of emotional intelligence.

Cognitive and emotional processes may be measured in different ways, but they are not distinct aspects of an individual's functioning, with increasing recognition and neurobiological understanding of their intertwine $(28,29)$. The interplay can be illustrated in processes such as emotional anxiety affecting attentional stimuli processing or disrupting working memory or chronic, unpredictable stress impairing behavioral flexibility in learning tests (30). Conversely, humans often use cognitive strategies to regulate their emotions such as through reappraisal of situations $(28,29)$. Thus, cognitive processing, emotions, and stress responses are intricately linked and impact an individual's functioning (28). Our understanding of the brain to date has predominantly come from research with humans and laboratory animals but there is the opportunity to both translate these findings to livestock for facilitating improvements in their housing environments, as well as increase our research specifically on livestock neural functioning.

\section{Impacts of Enrichments on Neural Development in Livestock}

The brain, whether human or animal, begins its development in utero, and henceforth it can be impacted by its surrounding environment (31). Maturation of neural circuits occurs throughout life making an individual brain a product of its 
experiences $(32,33)$. In particular, the neonatal period (the weeks directly after birth) is one of rapid neuronal formation including critical periods in which external stimuli can have maximal effect (34). However, neurogenesis and maturation does also occur in the adult brain (35). As the brain matures it is modulated by the sensory input it receives including social contact such as maternal care [e.g., (36)], exercise [e.g., (37)], cognitive stimulation (38) and physical enrichments vs. impoverished surroundings (39). There is clear evidence from decades of research with humans, laboratory animals, and fish that provision of an enriched, stimulatory environment during both rearing and adult periods has positive impacts on the development, maturation, and plasticity of the brain [see reviews in (40-42)]. Given the enormous complexity of the brain, a full understanding of the pathways involved and precise modes of impact are still under investigation.

Within livestock animals the neurobiological studies of enrichment impacts are fewer. This is possibly due to relatively greater difficulty in analyzing brain function in larger livestock species compared with laboratory rodents as well as the comparative infancy of the application of neurobiological techniques within the field of animal welfare research. There is some evidence that beneficial brain-derived neurotrophic factor (measured in plasma as a proxy for brain concentrations) increases in pigs with exposure to foraging enrichment relative to barren housing (43). Enriched housing of pigs with straw for foraging has also resulted in increases in proteins that indicate greater capacity for both protein synthesis and neuronal activity (44). Changes within monoaminergic neurotransmitters suggested enriched pigs showed lower stress responses to the slaughterhouse experience than those housed in the barren conditions (44). Long-term cognitive enrichment resulted in gene expression differences in reward-sensitive opioid receptors in the amygdala of pigs suggesting positive states were being experienced (45). Pigs exposed to enrichments also had higher dopamine levels in their striatum relative to pigs from barren housing conditions (46). Chickens with more optimistic judgement bias responses following unpredictable stressors showed greater dopamine turnover in the mesencephalon (47). Additionally, more chicks from enriched conditions maintained an optimistic bias following the stressors relative to chicks from barren rearing environments (47). Comparatively the literature on neurological impacts of environmental enrichment in laboratory animals is much vaster but livestock results to date do broadly align with what has been previously demonstrated in other species [e.g., (40, 48-50)].

\section{Impact of Enriched Rearing Environments on Cognitive Capacity, Emotions, and Stress Responses in Livestock}

Studies on the direct neurobiological impacts of enrichments in livestock animals are currently relatively limited. However, there is a large, and growing body of livestock research demonstrating enrichment impacts on indirect measures able to be taken on the whole living animal. These measures include cognition, affective states, judgement biases, and stress responses which behaviorally and physiologically support the underlying neurological changes that are likely occurring.

Physical enrichments and increased environmental complexity in chickens has been shown to reduce startle reactivity in young adults (51). Enrichment also improves chicks' responses to stress by buffering against more pessimistic judgement biases (47), reducing physiological stress and improving pro-inflammatory responses where increased swelling in response to an injected antigen is indicative of greater immunocompetence (52). Furthermore, enrichment during the rearing period will reduce fearfulness (53), and improve spatial cognition (54) in broilers and young adult hens, respectively, relative to those birds reared in more barren conditions which could have additional stress-reducing impacts. In calves, physical feeding enrichments can improve reversal learning and reduce reactive responses to novel stimuli (55). Both physical and cognitive enrichment in newly-weaned dwarf goats improve learning performance and exploration behavior (56). In pigs, environmental enrichments result in more optimistic judgement biases in gilts (57) and more rapid learning performance and better working memory in cognitive tasks in weaned piglets (58-60).

These (and other) studies highlight the positive cognitive and emotional impacts of providing enrichments across several livestock species, particularly during the developmental stages (i.e., before reaching sexual maturity or slaughter age for shorter-lived livestock animals such as meat birds, with the weeks directly after birth/hatching likely to be most critical). Furthermore, an enriched and more complex environment will reduce the occurrence of abnormal behaviors such as feather pecking in laying hens (61), locomotor stereotypies in mink (62), aggression and oral stereotypies in feedlot cattle (63) and oral stereotypies in dairy calves (64) which are all indicative of neural dysfunction (65). However, more research with livestock is needed to better understand the specific neural mechanisms of stereotypy development and how enrichment may exert its effect (66). Benefits are also not limited to just physical enrichments. For example, social enrichment in dairy cattle improved learning and performance in cognitive tasks (67) and there is growing interest in the provision of cognitive enrichment for livestock to facilitate mental engagement (68).

\section{Facilitating Animal Happiness}

Given the compelling evidence of the neurological impacts of enrichment across species, coupled with the drive toward positive welfare for agricultural animals $(8,9)$, provision of enrichments should be a necessity moving forward to enable animals to fulfill their neurological potential. Cognitive capacity is improved through enrichment that facilitates proper development of an animal's natural cognitive abilities (69). As defined earlier (see section Defining Cognition and Emotion) cognition is also inextricably linked with emotions, stress or coping mechanisms and thus mental health. We see from human literature, children raised in depauperate conditions with poorer stimulation (e.g., orphanages, low socio-economic status) show reduced cognitive development $(70,71)$ that can be mediated by cognitive stimulatory intervention programs (72). Deficits in the 
developmental years can then impact functioning as adults with lower cognition in childhood linked to poorer mental health as adults $(73,74)$ such as an increased risk of developing anxiety later in life (75). Adult individuals with lower intelligence may be at increased risk for developing anxiety disorders following highly stressful events, hypothesized to be due to a reduced ability to cope with adverse circumstances (76). Furthermore, individuals with a lower intelligence quotient (IQ) also report being less happy than those with higher IQ (77). This can in part be mediated by socioeconomic status where greater access to resources may improve happiness scores (77), highlighting the reciprocity of the relationship between IQ, resource access, and happiness. There is also a clear, documented relationship in humans between happiness and emotional intelligence where people with higher emotional intelligence will report greater happiness scores, potentially through being able to better regulate negative emotions and capitalize on positive ones (78-80). Greater emotional regulation correlates with improved happiness and socioeconomic status (81). Emotional intelligence has even been demonstrated to compensate for low IQ (82) and can be a greater predictor of overall well-being than IQ (83).

Applying this evidence from human literature to livestock animals, individuals without sufficient early cognitive stimulation may be more likely to develop negative affective states or behavioral problems such as aggression. These individuals could develop poorer emotional intelligence which could increase their susceptibility to negative emotions and reduce their ability to experience positive states. They may also be less equipped to cope with stressful events such as moving between housing stages, or changes in social companions. They may have increased anxiety if their cognitive capabilities do not align with housing system expectations such as high system complexity (e.g., laying hen aviaries), or learning requirements of precision technologies such as automatic milking systems or virtual fencing (84). There could then be flow-on emotional impacts if the animals are unable to utilize system resources effectively. Evidence of such described impacts following more barren rearing environments have been documented in livestock as highlighted previously (see section Impact of Enriched Rearing Environments on Cognitive Capacity, Emotions, and Stress Responses in Livestock).

Enrichment may thus facilitate appropriate neural development for greater emotional intelligence and more experiences of positive states, as well as result in positive emotions through the process of engaging with the enrichment itself. Evidence from livestock animals to date demonstrates the innate curiosity drive to engage with novel stimulation in their environment. Young livestock animals will show motivation to explore and play with their physical environment (85-88). In humans, the degree of curiosity can also be highly correlated with the degree of emotional intelligence $(89,90)$, thus highlighting the potential interdependence between enrichment provision to stimulate neural development and future engagement with enrichments. Livestock will also actively engage with cognitive enrichments [e.g., pigs: (91); laying hens: (92); dwarf goats: (93)], and show motivation to learn (94) as well as physiological evidence of learning processes being rewarding (95-97). This evidence of a natural desire for enrichment engagement supports the negative impacts that the absence of such stimulation would have.

\section{Challenges of Environmental Enrichment and Future Strategic Enrichment Directions}

While clear benefits of enrichment provision for livestock have been outlined, potential shortcomings of enrichment must be considered. By necessity, animals are in "unnatural" conditions where scientists, consumers, and stakeholders recognize that in many cases this can be sub-optimal for animal welfare. The challenge that researchers and livestock producers face, is the conundrum of trying to "fix" animals so that they have "natural" functioning, in ultimately what will likely always be "unnatural" conditions that place different demands on the animal than what their wild counterparts experience. For example, production animals may not have to select food, evade predators, find mates, or rear young, but do have to adapt to invasive husbandry practices, human interaction, reduced habitat choice, and reduced social choice.

Logistically, enrichment provision can be challenging under the constraints of commercial animal production and environmental control for proper health care. Enrichments may be able to be provided during rearing, but not in adult stages due to changes in housing environments, and/or management requirements. Or enrichments may be rapidly damaged/consumed resulting in limited opportunities for interactions. Removal of enrichment access has been shown to induce negative cognitive states relative to animals that never had enrichment access (57) and can decrease positive exploratory behaviors (98). Removal of enrichments may also induce inactivity which can be indicative of boredom (99, 100). High degrees of novelty in enrichment provision may have detrimental effects on neophobic individuals (101). Furthermore, high stimulation to promote extensive neural development could result in over-active brains that may actually have adverse impacts. In contrast with positive correlations between IQ and happiness in humans, some recent human-based evidence indicates that very high IQ (hyper brain) may increase the risk of mental and physical health problems such as anxiety and immune dysfunction (102). It is suggested that a hyper brain corresponds with hyper excitability of the body resulting in detrimental impacts (102). Intense enrichment provision may not extend the animal beyond their natural capacity as animal species will have neurological limitations, although we may not yet know precisely what these are (103). However, it is unknown whether intense enrichment would have similar "hyper brain" affective and physiological impacts in livestock animals or if these impacts are limited to the complexities of human nature and societal demands. Furthermore, intense enrichment within developmental periods may boost cognitive development to such a point that animals require more stimulation than can be provided by the environments they are subsequently housed in; potentially resulting in detrimental boredom states (104). Thus, a highly developed brain may suffer more in an only moderately stimulating environment, a hypothesis that warrants testing.

Consequently, strategic enrichment programs may provide a partial solution to both improved and positive animal welfare if 
they enable livestock animals to fulfill their neurological potential within their specific housing constraints, including adequately adapting to and coping with the production setting. Application of enrichments in terms of the type and timing to target key neurological developmental periods and pathways that may be most utilized with specific types of housing or management situations is likely to result in the greatest positive impacts on animal welfare. Targeted environmental and/or cognitive stimulation applied during rearing could optimize neurological development in the current conditions as well as best prepare the animals for their future housing system. By identifying the pertinent potential stressors the animals may encounter (e.g., frequent social change), or skills they may need (e.g., learning of technologies) enrichments targeted to develop the necessary specific brain areas or specific skills could enable animals to best adapt to their environment. This type of developmental strategy is being employed in some livestock management practices. For example, laying hens destined for aviary systems that require spatial navigation, are reared with ramps that facilitate the development of these skills (105). Different indoor rearing enrichment strategies will have contrasting impacts on how the adult hens utilize the outdoor area of a free-range system (106). Pigs reared with environmental enrichments as well as socialization show reduced stress and aggression following social remixing throughout life (107). However, there is great scope to better understand the neurological impacts that are occurring when animals experience specific types of enrichments (108) to optimize enrichment strategies further.

The notion of specific types of neurological development being better suited to specific types of environments has previously been suggested, where animals with differing hemispheric dominance may better cope with specific types of environments due to varying cognitive biases (109). Left hemispheric dominance is suggested to result in better coping with chronic stress situations (109), although ultimately the goal for improved livestock welfare is to avoid housing conditions that are likely to elicit chronic stress responses. Similar affective state frameworks have been presented for emotional lateralization and how this may impact animal reactivity and welfare (110). However, there is great scope for further research in this area to enhance the welfare of livestock species. Enrichments that are species relevant as well as housing environment relevant will likely have maximal benefit. Potential brain areas/skills of relevance could include cognitive flexibility. This flexibility is primarily through enhancement of the prefrontal cortex but can extend across other brain regions [reviewed in (111)] and could be important for animals that have to continuously adapt to

\section{REFERENCES}

1. Proctor HS, Carder G, Cornish AR. Searching for animal sentience? A systematic review of the scientific literature. Animals. (2013) 3:882-906. doi: $10.3390 /$ ani3030882

2. Doyle, R. (2017). Sheep cognition and its implications for welfare. In: Ferguson DM, Lee C, Fisher A, editors. Advances in Sheep Welfare (Elsevier Ltd; Woodhead Publishing). p. 55-71. doi: 10.1016/B978-0-08-100718-1.00004-2 changing environmental conditions such as free-range housing systems. Social enrichment may modify the hypothalamicadrenal-pituitary axis and reduce subsequent emotional reactions to stress (112), thereby improving coping in animals that undergo stressful management procedures. Enhancement of the hippocampus may be beneficial to animals which require high spatial abilities in navigating their housing systems (113). However, these are simplified examples drawn from the extensive research conducted in laboratory animals. Further research with livestock accompanied by cross-disciplinary discussion with neuroscientists will maximize the benefits of enrichment strategies. Finally, further research on how enrichment during rearing conditions affects the brain of livestock animals will improve our understanding of more generalized benefits. Pairhousing in calves has been shown to improve adaptation during the weaning period (114) and cognitive performance in learning tests (67), indicating certain types of enrichment may translate across different areas of functioning to have multiple benefits to the animals.

In conclusion, this perspective highlights the importance of further research to understand the neurological impacts of different types of enrichments for livestock animals so we can ensure strategic enrichment programs are developed to best suit specific environments and experiences animals are likely to encounter. Enabling development of their cognitive and emotional intelligence should minimize negative affect and facilitate positive welfare states.

\section{DATA AVAILABILITY STATEMENT}

The original contributions presented in the study are included in the article/supplementary material, further inquiries can be directed to the corresponding author/s.

\section{AUTHOR CONTRIBUTIONS}

DC and CL conceived the ideas. DC wrote the first draft. CL provided feedback and both authors agreed to the final manuscript. Both authors contributed to the article and approved the submitted version.

\section{FUNDING}

Open Access Publication fees were funded by the Commonwealth Scientific and Industrial Research Organisation (CSIRO) through a Julius Career Award to DC.
3. Marino L. Thinking chickens: a review of cognition, emotion, and behavior in the domestic chicken. Anim Cogn. (2017) 20:127-47. doi: 10.1007/s10071-016-1064-4

4. Marino L, Colvin CM. Thinking pigs: a comparative review of cognition, emotion, and personality in Sus domesticus. Int J Compar Psychol. (2015) 28:23859. doi: 10.46867/ijcp.2015. 28.00.04

5. Nawroth C, Langbein J, Coulon M, Gabor V, Oestermind S, BenzSchwarzburg J, et al. Farm animal cognition - linking behavior, 
welfare and ethics. Front Vet Sci. (2019) 6:24. doi: 10.3389/fvets.2019. 00024

6. Crump A, Arnott G, Bethell EJ. Affect-driven attention biases as animal welfare indicators: review and methods. Animals. (2018) 8:136. doi: $10.3390 /$ ani8080136

7. Lecorps B, Weary DM, von Keyserlingk MAG. Captivity-induced depression in animals. Trends Cogn Sci. (2021) 25:539-41. doi: 10.1016/j.tics.2021.03.010

8. Mellor DJ. Enhancing animal welfare by creating opportunities for positive affective engagement. $N$ Z Vet $J$. (2015) 63:3-8. doi: 10.1080/00480169.2014.926799

9. Mellor DJ. Positive animal welfare states and encouraging environmentfocused and animal-to-animal interactive behaviours. N Z Vet J. (2015) 63:9-16. doi: 10.1080/00480169.2014.926800

10. Dawkins MS. Behaviour as a tool in the assessment of animal welfare. Zoology. (2003) 106:383-7. doi: 10.1078/0944-2006-00122

11. Ridge EE, Foster MJ, Daigle CL. Effect of diet on non-nutritive oral behavior performance in cattle: a systematic review. Livest Sci. (2020) 238:104063. doi: 10.1016/j.livsci.2020.104063

12. D'Eath RB, Arnott G, Turner SP, Jensen T, Lahrmann HP, Busch $\mathrm{ME}$, et al. Injurious tail biting in pigs: how can it be controlled in existing systems without tail docking? Animal. (2014) 8:1479-97. doi: $10.1017 /$ S1751731114001359

13. Cronin GM, Glatz PC. Causes of feather pecking and subsequent welfare issues for the laying hen: a review. Anim Prod Sci. (2020) 61:990-1005. doi: 10.1071/AN19628

14. Bloomsmith MA, Brent LY, Schapiro SJ. Guidelines for developing and managing an environmental enrichment program for nonhuman primates. Lab Anim Sci. (1991) 41:372-7.

15. Newberry RC. Environmental enrichment: increasing the biological relevance of captive environments. Appl Anim Behav Sci. (1995) 44:229-43. doi: 10.1016/0168-1591(95)00616-Z

16. Appleby MC. The European Union band on conventional cages for laying hens: history and prospects. J Appl Anim Welfare Sci. (2003) 6:103-21. doi: 10.1207/S15327604JAWS0602_03

17. National Farm Animal Care Council. Code of Practice for the Care and Handling of Farmed Mink. ON, Canada: Canada Mink Breeders Association (2013).

18. de Haas EN, Bolhuis JE, Kemp B, Groothuis TGG, Rodenburg TB. Parents and early life environment affect behavioral development of laying hen chickens. PLoS ONE. (2014) 9:e90577. doi: 10.1371/journal.pone.00 90577

19. Salovey P, Mayer JD. Emotional intelligence. Imagin Cogn Pers. (1989-1990) 9:185-211. doi: 10.2190/DUGG-P24E-52WK-6CDG

20. Petrides KV, Furnham A. On the dimensional structure of emotional intelligence. Pers Individ Dif. (2000) 29:313-20. doi: 10.1016/S0191-8869(99)00195-6

21. O'Connor PJ, Hill A, Kaya M, Martin B. The measurement of emotional intelligence: a critical review of the literature and recommendations for researchers and practitioners. Front Psychol. (2019) 10:1116. doi: 10.3389/fpsyg.2019.01116

22. de Jonge FH, Tilly SL, Baars AM, Spruijt BM. On the rewarding nature of appetitive feeding behaviour in pigs (Sus scrofa): do domesticated pigs contrafreeload? Appl Anim Behav Sci. (2008) 114:359-72. doi: 10.1016/j.applanim.2008.03.006

23. Ede T, von Keyserlingk MAG, Weary DM. Assessing the affective component of pain, and the efficacy of pain control, using conditioned place aversion in calves. Biol Lett. (2019) 15:20190642. doi: 10.1098/rsbl.2019.0642

24. Paul ES, Edgar JL, Caplen G, Nicol CJ. Examining affective structure in chickens: valence, intensity, persistence and generalization measured using a Conditioned Place Preference Test. Appl Anim Behav Sci. (2018) 207:39-48. doi: 10.1016/j.applanim.2018.07.007

25. Reimert I, Bolhuis JE, Kemp B, Rodenburg TB. Indicators of positive and negative emotions and emotional contagion in pigs. Physiol Behav. (2013) 109:42-50. doi: 10.1016/j.physbeh.2012.11.002

26. Reimert I, Fong S, Rodenburg TB, Bolhuis JE. Emotional states and emotional contagion in pigs after exposure to a positive and negative treatment. Appl Anim Behav Sci. (2017) 193:37-42. doi: 10.1016/j.applanim.2017.03.009
27. Edgar JL, Nicol CJ, Clark CCA, Paul ES. Measuring empathic responses in animals. Appl Anim Behav Sci. (2012) 138:182-93. doi: 10.1016/j.applanim.2012.02.006

28. Okon-Singer H, Handler T, Pessoa L, Shackman AJ. The neurobiology of emotion-cognition interactions: fundamental questions and strategies for future research. Front Neurosci. (2015) 9:58. doi: 10.3389/fnhum.2015.00058

29. Pessoa L. On the relationship between emotion and cognition. Nat Rev Neurosci. (2008) 9:148-58. doi: 10.1038/nrn2317

30. Hurtubise JL, Howland JG. Effects of stress on behavioral flexibility in rodents. Neuroscience. (2017) 345:187-92. doi: 10.1016/j.neuroscience.2016.04.007

31. Sale A, Berardi N, Maffei L. Environmental enrichment and brain development. In: Sale A, editors. Environmental Experience and Plasticity of the Developing Brain. Hoboken, NJ: John Wiley \& Sons, Inc. (2016). p. 1-26.

32. Kempermann G. Environmental enrichment, new neurons and the neurobiology of individuality. Nat Rev Neurosci. (2019) 20:235-45. doi: 10.1038/s41583-019-0120-x

33. Tamnes, C. K. Postnatal brain maturation. Ref Module Neurosci Biobehav Psychol. (2017). doi: 10.1016/B978-0-12-809324-5.02978-3. [Epub ahead of print].

34. Hübener M, Bonhoeffer T. Neuronal plasticity: beyond the critical period. Cell. (2014) 159:727-37. doi: 10.1016/j.cell.2014.10.035

35. Toda T, Gage FH. Review: adult neurogenesis contributes to hippocampal plasticity. Cell Tissue Res. (2018) 373:693-709. doi: 10.1007/s00441-017-2735-4

36. Nishi M, Horii-Hayashi N, Sasagawa T, Matsunaga W. Effects of early life stress on brain activity: implications from maternal separation model in rodents. Gen Comp Endocrinol. (2013) 181:306-9. doi: 10.1016/j.ygcen.2012.09.024

37. Voss MW, Nagamatsu LS, Liu-Ambrose T, Kramer AF. Exercise, brain, and cognition across the life span. J Appl Physiol. (2011) 111:1505-13. doi: 10.1152/japplphysiol.00210.2011

38. Schoentgen B, Gagliardi G, Défontaines B. Environmental and cognitive enrichment in childhood as protective factors in the adult and aging brain. Front Psychol. (2020) 11:1814. doi: 10.3389/fpsyg.2020.01814

39. Ohline SM, Abraham WC. Environmental enrichment effects on synaptic and cellular physiology of hippocampal neurons. Neuropharmacology. (2019) 145:3-12. doi: 10.1016/j.neuropharm.2018.04.007

40. Clemenson GD, Deng W, Gage FH. Environmental enrichment and neurogenesis: from mice to humans. Curr Opin Behav Sci. (2015) 4:56-62. doi: 10.1016/j.cobeha.2015.02.005

41. Sale A, Berardi N, Maffei L. Environment and brain plasticity: towards an endogenous pharmacotherapy. Physiol Rev. (2014) 94:189-234. doi: 10.1152 /physrev.00036.2012

42. Van Praag H, Kempermann G, Gage FH. Neural consequences of environmental enrichment. Nat Rev Neurosci. (2000) 1:191-8. doi: $10.1038 / 35044558$

43. Rault J-L, Lawrence AJ, Ralph CR. Brain-derived neurotrophic factor in serum as an animal welfare indicator of environmental enrichment in pigs. Domest Anim Endocrinol. (2018) 65:67-70. doi: 10.1016/j.domaniend.2018.05.007

44. Arroyo L, Valent D, Carreras R, Pato R, Sabrià J, Velarde A, et al. Neurobiology of environmental enrichment in pigs: changes in monoaminergic neurotransmitters in several brain areas and in the hippocampal proteome. J Proteom. (2020) 229:103943. doi: 10.1016/j.jprot.2020.103943

45. Kalbe C, Puppe B. Long-term cognitive enrichment affects opioid receptor expression in the amygdala of domestic pigs. Genes Brain Behavior. (2010) 9:75-83. doi: 10.1111/j.1601-183X.2009.00536.X

46. Marsh L, Hutchinson MR, McLaughlan C, Musolino ST, Hebart ML, Terry $\mathrm{R}$, et al. Evaluation of miRNA as biomarkers of emotional valence in pigs. Animals. (2021) 11:2054. doi: 10.3390/ani11072054

47. Zidar J, Campderrich I, Jansson E, Wichman A, Winberg S, Keeling L, et al. Environmental complexity buffers against stress-induced negative judgement bias in female chickens. Sci Rep. (2018) 8:5404. doi: 10.1038/s41598-018-23545-6

48. Gelfo F, Mandolesi L, Serra L, Sorrentino G, Caltagirone C. The neuroprotective effects of experience on cognitive functions: evidence from 
animal studies on the neurobiological bases of brain reserve. Neuroscience. (2018) 370:281-35. doi: 10.1016/j.neuroscience.2017.07.065

49. Mora F, Segovia G, del Arco A. Aging, plasticity and environmental enrichment: structural changes and neurotransmitter dynamics in several areas of the brain. Brain Res Rev. (2007) 55:78-88. doi: 10.1016/j.brainresrev.2007.03.011

50. Novkovic T, Mittmann T, Manahan-Vaughan D. BDNF contributes to the facilitation of hippocampal synaptic plasticity and learning enabled by environmental enrichment. Hippocampus. (2014) 25:1-15. doi: $10.1002 /$ hipo. 22342

51. Ross M, Rausch Q, Vandenberg B, Mason G. Hens with benefits: can environmental enrichment make chickens more resilient to stress? Physiol Behav. (2020) 226:113077. doi: 10.1016/j.physbeh.2020.113077

52. Campderrich I, Nazar FN, Wichman A, Marin RH, Estevez I, Keeling LJ. Environmental complexity: a buffer against stress in the domestic chick. PLoS ONE. (2019) 14:e0210270. doi: 10.1371/journal.pone.0210270

53. Tahamtani FM, Pedersen IJ, Toinon C, Riber AJ. Effects of environmental complexity on fearfulness and learning ability in fast growing broiler chickens. Appl Anim Behav Sci. (2018) 207:49-56. doi: 10.1016/j.applanim.2018.04.005

54. Tahamtani FM, Nordgreen J, Nordquist RE, Janczak AM. Early life in a barren environment adversely affects spatial cognition in laying hens (Gallus gallus domesticus). Front Vet Sci. (2015) 2:3. doi: 10.3389/fvets.2015.00003

55. Horvath K, Fernandez M, Miller-Cushon EK. The effect of feeding enrichment in the milk-feeding stage on the cognition of dairy calves in a T-maze. Appl Anim Behav Sci. (2017) 187:8-14. doi: 10.1016/j.applanim.2016.11.016

56. Oesterwind S, Nürnberg G, Puppe B, Langbein J. Impact of structural and cognitive enrichment on the learning performance, behavior and physiology of dwarf goats (Capra aegagrus hircus). Appl Anim Behav Sci. (2016) 177:3441. doi: 10.1016/j.applanim.2016.01.006

57. Douglas C, Bateson M, Walsh C, Bédué A, Edwards SA. Environmental enrichment induces optimistic cognitive biases in pigs. Appl Anim Behav Sci. (2012) 139:65-73. doi: 10.1016/j.applanim.2012.02.018

58. Bolhuis JE, Oostindjer M, Hoeks CWF, de Haas EN, Bartels AC, Ooms $\mathrm{M}$, et al. Working and reference memory of pigs (Sus scrofa domesticus) in a holeboard spatial discrimination task: the influence of environmental enrichment. Anim Cogn. (2013) 16:845-50. doi: 10.1007/s10071-013-0646-7

59. Grimberg-Henrici CGE, Vermaak P, Bolhuis JE, Nordquist RE, van der Staay FJ. Effects of environmental enrichment on cognitive performance of pigs in a spatial holeboard discrimination task. Anim Cogn. (2016) 19:271-83. doi: 10.1007/s10071-015-0932-7

60. Sneddon IA, Beattie VE, Dunne L, Neil W. The effect of environmental enrichment on learning in pigs. Anim Welfare. (2000) 9:373-83.

61. Schreiter R, Damme K, von Borell E, Vogt I, Klunker M, Freick M. Effects of litter and additional enrichment elements on the occurrence of feather pecking in pullets and laying hens - a focused review. Vet Med Sci. (2019) 5:500-7. doi: $10.1002 / \mathrm{vms} 3.184$

62. Díez-León M, Bowman J, Bursian S, Filion H, Galicia D, Kanefsky $J$, et al. Environmentally enriched male mink gain more copulations than stereotypic, barren-reared competitors. PLoS ONE. (2013) 8:380494. doi: 10.1371/journal.pone.0080494

63. Park RM, Schubach KM, Cooke RF, Herring AD, Jennings JS, Daigle CL. Impact of a cattle brush on feedlot steer behavior, productivity and stress physiology. Appl Anim Behav Sci. (2019) 228:104995. doi: 10.1016/j.applanim.2020.104995

64. Horvath KC, Allen AN, Miller-Cushon EK. Effect of access to stationary brushes and chopped hay on behavior and performance of individually housed dairy calves. J Dairy Sci. (2020) 103:8421-32. doi: 10.3168/jds.2019-18042

65. Péter Z, Oliphant ME, Fernandez TV. Motor stereotypies: a pathophysiological review. Front Neurosci. (2017) 11:171. doi: $10.3389 /$ fnins.2017.00171

66. Díez-León M, Kitchenham L, Duprey R, Bailey CDC, Choleris E, Lewis M, et al. Neurophysiological correlates of stereotypic behaviour in a model carnivore species. Behav Brain Res. (2019) 373:112056. doi: 10.1016/j.bbr.2019.112056
67. Gaillard C, Meagher RK, von Keyserlingk MAG, Weary DM. Social housing improves dairy calves' performance in two cognitive tests. PLoS ONE. (2014) 9:e90205. doi: 10.1371/journal.pone.0090205

68. Clark FE. Cognitive enrichment and welfare: current approaches and future directions. Anim Behav Cogn. (2017) 4:52-71. doi: 10.12966/abc.05.02.2017

69. Zentall TR. Effect of environmental enrichment on the brain and on learning and cognition by animals. Animals. (2021) 11:973. doi: 10.3390/ani11040973

70. Escueta M, Whetten K, Ostermann J, O’Donnell K, The Positive Outcomes for Orphans (POFO) Research Team. Adverse childhood experiences, psychosocial well-being and cognitive development among orphans and abandoned children in five low income countries. BMC Int Health Hu Rights. (2014) 14:6. doi: 10.1186/1472-698X-14-6

71. Obradović J, Yousafzai AK, Finch JE, Rasheed MA. Maternal scaffolding and home stimulation: key mediators of early intervention effects on children's cognitive development. Dev Psychol. (2016) 52:1409-21. doi: $10.1037 / \operatorname{dev} 0000182$

72. Burger K. How does early childhood care and education affect cognitive development? An international review of the effects of early interventions for children from different social backgrounds. Early Childhood Res Q. (2010) 25:140-65. doi: 10.1016/j.ecresq.2009.11.001

73. Barnett JH, McDougall F, Xu MK, Croudace TJ, Richards M, Jones PB. Childhood cognitive function and adult psychopathology: associations with psychotic and non-psychotic symptoms in the general population. $\mathrm{Br}$ J Psychiatry. (2012) 201:124-30. doi: 10.1192/bjp.bp.111.102053

74. Karestan C, Moffitt TE, Roberts AL, Martin LT, Kubzansky L, Harrington $\mathrm{H}$, et al. Childhood IQ and adult mental disorders: a test of the cognitive reserve hypothesis. Am J Psychiatry. (2009) 166:50-7. doi: 10.1176/appi.ajp.2008.08030343

75. Martin LT, Kubzansky LD, LeWinn KZ, Lipsitt LP, Satz P, Buka SL. Childhood cognitive performance and risk of generalized anxiety disorder. Int J Epidemiol. (2007) 36:769-75. doi: 10.1093/ije/dym063

76. Macklin ML, Metzger LJ, Litz BT, McNally RJ, Lasko NB, Orr SP, et al. Lower precombat intelligence is a risk factor for posttraumatic stress disorder. J Consult Clin Psychol. (1998) 66:323-6. doi: 10.1037/0022-006X.66.2.323

77. Ali A, Ambler G, Strydom A, Rai D, Cooper C, McManus S, et al. The relationship between happiness and intelligent quotient: the contribution of socio-economic and clinical factors. Psychol Med. (2013) 43:1303-12. doi: $10.1017 /$ S0033291712002139

78. Callea A, De Rosa D, Ferri G, Lipari F, Costanzi M. Are more intelligent people happier? Emotional intelligence as mediator between need for relatedness, happiness and flourishing. Sustainability. (2019) 11:1022. doi: 10.3390/su11041022

79. Szczygieł D, Mikolajczak M. Why are people high in emotional intelligence happier? They make the most of their positive emotions. Pers Indiv Diff. (2017) 117:177-81. doi: 10.1016/j.paid.2017.05.051

80. Zacher H, McKenna B, Rooney D. Effects of self-reported wisdom on happiness: not much more than emotional intelligence? J Happiness Stud. (2013) 14:1697-716. doi: 10.1007/s10902-012-9404-9

81. Côté S, Gyurak A, Levenson RW. The ability to regulate emotion is associated with greater well-being, income, and socioeconomic status. Emotion. (2010) 10:923-33. doi: 10.1037/a0021156

82. Fiori M. Emotional intelligence compensates for low IQ and boosts low emotionality individuals in a self-presentation task. Pers Individ Dif. (2015) 81:169-73. doi: 10.1016/j.paid.2014.08.013

83. Dimitrijević AA, Marjanović ZJ, Dimitrijević A. Whichever intelligence makes you happy: the role of academic, emotional, and practical abilities in predicting psychological well-being. Pers Indiv Diff. (2018) 132:6-13. doi: $10.1016 /$ j.paid.2018.05.010

84. Lee C, Colditz IG, Campbell DLM. A framework to assess the impact of new animal management technologies on welfare: a case study of virtual fencing. Front Vet Sci. (2018) 5:187. doi: 10.3389/fvets.2018.00187

85. Jensen MB. The early behaviour of cow and calf in an individual calving pen. Appl Anim Behav Sci. (2011) 124:92-9. doi: 10.1016/j.applanim.2011.06.017

86. Newberry RC, Wood-Gush DGM, Hall JW. Playful behaviour of piglets. Behav Processes. (1988) 17:205-16. doi: 10.1016/0376-6357(88)90004-6

87. Newberry RC. Exploratory behaviour of young domestic fowl. Appl Anim Behav Sci. (1999) 63:311-21. doi: 10.1016/S0168-1591(99)00016-7 
88. Wood-Gush DGM, Vestergaard K. The seeking of novelty and its relation to play. Anim Behav. (1991) 42:599-606. doi: 10.1016/S0003-3472(05) 80243-X

89. Leonard $\mathrm{NH}$, Harvey $\mathrm{M}$. The trait of curiosity as a predictor of emotional intelligence. J Appl Soc Psychol. (2007) 37:1545-61. doi: 10.1111/j.1559-1816.2007.00226.x

90. Mohanty A, Pradhan RK, Jena LK. Curiosity and the meaning of life leading towards personal growth: the role of emotional intelligence. J Indian Acad Appl Psychol. (2015) 41:226-35.

91. Sonoda LT, Fels M, Rauterberg S, Viazzi S, Ismayilova G, Oczak M, et al. Cognitive enrichment in piglet rearing: an approach to enhance animal welfare and to reduce aggressive behaviour. ISRN Vet Sci. (2013) 2013:389186. doi: 10.1155/2013/389186

92. Schmelz M, Krause ET. Simple but complex - A laying hen study as proof of concept of a novel method for cognitive enrichment and research. Front Anim Sci. (2021) 2:671905. doi: 10.3389/fanim.2021.671905

93. Langbein J, Siebert K, Nürnberg G. On the use of an automated learning device by group-housed dwarf goats: do goats seek cognitive challenges? Appl Anim Behav Sci. (2009) 120:150-8. doi: 10.1016/j.applanim.2009.07.006

94. Meagher RK, Strazhnik E, von Keyserlingk MAG, Weary DM. Assessing the motivation to learn in cattle. Sci Rep. (2020) 10:6847. doi: 10.1038/s41598-020-63848-1

95. Hagen K, Broom DM. Emotional reactions to learning in cattle. Appl Anim Behav Sci. (2004) 85:203-13. doi: 10.1016/j.applanim.2003.11.007

96. Langbein J, Nürnberg G, Manteuffel G. Visual discrimination learning in dwarf goats and associated changes in heart rate and heart rate variability. Physiol Behav. (2004) 82:601-9. doi: 10.1016/j.physbeh.2004.05.007

97. Zebunke M, Langbein J, Manteuffel G, Puppe B. Autonomic reactions indicating positive affect during acoustic reward learning in domestic pigs. Anim Behav. (2011) 81:481-9. doi: 10.1016/j.anbehav.2010.11.023

98. Melotti L, Oostindjer M, Bolhuis JE, Held S, Mendl M. Coping personality type and environmental enrichment affect aggression at weaning in pigs. Appl Anim Behav Sci. (2011) 133:144-53. doi: 10.1016/j.applanim.2011.05.018

99. Bolhuis JE, Schouten WGP, Schrama JW, Wiegant VM. Effects of rearing and housing environment on behaviour and performance of pigs with different coping characteristics. Appl Anim Behav Sci. (2006) 101:68-85. doi: 10.1016/j.applanim.2006.01.001

100. Meagher RK, Campbell DLM, Dallaire JA, Díez-León M, Palme R, Mason GJ. Sleeping tight or hiding in fright? The welfare implications of different subtypes of inactivity in mink. Appl Anim Behav Sci. (2013) 144:138-46. doi: 10.1016/j.applanim.2013.01.008

101. Fox RA, Millam JR. Novelty and individual differences influence neophobia in orange-winged Amazon parrots (Amazona amazonica). Appl Anim Behav Sci. (2007) 104:107-15. doi: 10.1016/j.applanim.2006.04.033

102. Karpinski RI, Kinase Kolb AM, Tetreault NA, Borowski TB. High intelligence: A risk factor for psychological and physiological overexcitabilities. Intelligence. (2018) 66:8-23. doi: 10.1016/j.intell.2017.09.001

103. Columbo M, Scarf D. Are there differences in 'Intelligence' between nonhuman species? The role of contextual variables. Front Psychol. (2020) 11:2072. doi: 10.3389/fpsyg.2020.02072

104. Meagher RK. Is boredom an animal welfare concern? Animal Welfare. (2018) 28:21-32. doi: 10.7120/09627286.28.1.021
105. Norman KI, Weeks CA, Tarlton JF, Nicol CJ. Rearing experience with ramps improves specific learning and behaviour and welfare on a commercial laying farm. Sci Rep. (2021) 11:8860. doi: 10.1038/s41598-021-88347-9

106. Campbell DLM, Dyall TR, Downing JA, Cohen-Barnhouse AM, Lee C. Rearing enrichments affected ranging behavior in free-range laying hens. Front Vet Sci. (2020) 7:446. doi: 10.3389/fvets.2020.00446

107. Ko H-L, Chong Q, Escribano D, Camerlink I, Manteca X, Llonch P. Pre-weaning socialization and environmental enrichment affect life-long response to regrouping in commercially-reared pigs. Appl Anim Behav Sci. (2020) 229:105044. doi: 10.1016/j.applanim.2020.105044

108. Ryding S, Garnham LC, Abbey-Lee RN, Petkova I, Kreshchenko A, Løvlie H. Impulsivity is affected by cognitive enrichment and links to brain gene expression in red junglefowl chicks. Anim Behav. (2021) 178:195-207. doi: 10.1016/j.anbehav.2021.06.007

109. Rogers LJ. Relevance of brain and behavioural lateralization to animal welfare. Appl Anim Behav Sci. (2010) 127:1-11. doi: 10.1016/j.applanim.2010.06.008

110. Goursot C, Düpjan S, Puppe B, Leliveld LMC. Affective styles and emotional lateralization: a promising framework for animal welfare research. Appl Anim Behav Sci. (2021) 237:105279. doi: 10.1016/j.applanim.2021.105279

111. Gelfo F. Does experience enhance cognitive flexibility? An overview of the evidence provided by the environmental enrichment studies. Front Behav Neurosci. (2019) 13:150. doi: 10.3389/fnbeh.2019.00150

112. Cirulli F, Berry A, Tommaso Bonsignore LT, Capone F, D’Andrea I, Aloe L, et al. Early life influences on emotional reactivity: evidence that social enrichment has greater effects than handling on anxiety-like behaviors, neuroendocrine responses to stress and central BDNF levels. Neurosci Biobehav Rev. (2010) 34:808-20. doi: 10.1016/j.neubiorev.2010.02.008

113. Eckert MJ, Abraham WC. Effects of environmental enrichment exposure on synaptic transmission and plasticity in the hippocampus. In: Belzung C, Wigmore P, editors. Neurogenesis and Neural Plasticity. Current Topics in Behavioral Neuroscience. Vol 15. Berline, Heidelberg: Springer (2012).

114. De Paula Vieira A, von Keyserlingk MAG, Weary DM. Effects of pair versus single housing on performance and behavior of dairy calves before and after weaning from milk. J Dairy Sci. (2010) 93:3079-85. doi: $10.3168 /$ jds.2009-2516

Conflict of Interest: The authors declare that the research was conducted in the absence of any commercial or financial relationships that could be construed as a potential conflict of interest.

Publisher's Note: All claims expressed in this article are solely those of the authors and do not necessarily represent those of their affiliated organizations, or those of the publisher, the editors and the reviewers. Any product that may be evaluated in this article, or claim that may be made by its manufacturer, is not guaranteed or endorsed by the publisher.

Copyright (c) 2021 Campbell and Lee. This is an open-access article distributed under the terms of the Creative Commons Attribution License (CC BY). The use, distribution or reproduction in other forums is permitted, provided the original author(s) and the copyright owner(s) are credited and that the original publication in this journal is cited, in accordance with accepted academic practice. No use, distribution or reproduction is permitted which does not comply with these terms. 